\title{
RICARDO BOFILL: A ARQUITETURA DO CONTRASTE
}

Amanda Carolina Felício Vantini, Henrique Belorte, Jean Guilherme Oliveira, Korina Aparecida Teixeira Ferreira da Costa.

Universidade do Oeste Paulista - Unoeste, Curso de Arquitetura e Urbanismo, Presidente Prudente, SP. E-mail: korina.arq@gmail.com

\section{RESUMO}

O seguinte artigo, fruto de uma pesquisa qualitativa da espécie revisão bibliográfica, visa apresentar a vida e obra de Ricardo Bofill. Nascido em Barcelona 1939, cria a Taller Architecture em 1963, estúdio que conta com vários profissionais de outras áreas, contribuindo para a formação de seu estilo projetual pós-modernista. Além disso, toma como recorte analisar o edifício Walden 7, datado de 1974, localizado em Barcelona, o qual possui cores vivas e fortes, de caráter formalista faz uso de materiais industrializados realizando releituras da arquitetura mediterrânea, clássica e catalã através de uma construção pós-moderna. Assim, esta pesquisa tem como objetivo apresentar a forma como foi desenvolvido o estudo sobre o contexto da época e mostrar as características arquitetônicas de Bofill, destacando no objeto de estudo e expondo sua história enquanto arquiteto da pós-modernidade.

Palavras-chave: pós-modernidade, arquitetura historicista, formalismo, moradia vertical, Walden 7.

\section{RICARDO BOFILL: THE CONTRAST ARCHITECTURE}

\section{ABSTRACT}

The following article, result of a qualitative research, of the bibliographic vision species, focus on presenting the life and work of Ricardo Bofill. Born in Barcelona in 1939, 1963 creates the Taller Architecture, studio that counts with many professionals from another areas, contributing to the formation of your post-modern project style. Futhermore, takes as cutting analyze the building Walden 7 (1974), located in Barcelona, which has vivid colors, srtong formalist character, use of industrialized materials that realizes reads of mediterranean, classic and catalan architecture, through a post-modern construction. Therefore, this search has as objective to present a study about the time's context, and show Boffil's architetural characteristics, highlighting in the study's object and exposing your history as a post-modern architect.

Keywords: Post-modernity, historicist architecture, formalism, vertical habitation, Walden 7. 


\section{INTRODUÇÃO}

Em meados do século $X X$ o mundo foi cenário de grandes transformações $e$ manifestações que abalaram todo o mundo devido à 20 Guerra Mundial. A insatisfação com as técnicas e normas providas da Revolução Industrial acarretou em um questionamento por parte da sociedade que acreditava que a excessiva confiança na razão e na visão mecanicista que o Movimento Moderno pregava era ineficaz para a época. Com a arquitetura não foi diferente. Logo, o pós-modernismo foi identificado não como um movimento isolado, mas como uma nova estrutura social, efeito da globalização, onde as diversas áreas da sociedade passaram a estabelecer inter-relações, responsável por significativas mudanças presentes até hoje.

Entender o conceito de pós-modernidade requer uma análise de diversos fatores sociais. Para Esperandio (2007) não há como definir o que é o pós-moderno, no entanto, é possível ser refletido sobre os elementos que compõe este estilo. Já para Giddens (1991) e Fredric Jamenson (2011) a Pós-Modernidade surge do esgotamento e superação da Modernidade que buscava uma forma diferente de arquitetura, menos severa e decorativa, liberta dos efeitos perversos da época anterior.

Portoghesi (2002, p. 30) aponta que um dos motivos do pós-modernismo é:

[...] a necessidade de rever, e de algum modo relacionar, os eventos que estão ocorrendo, ou ocorreram, no olimpo da alta cultura e no nosso mundo cotidiano, nas cidades que habitamos, no território que transformamos (muitas vezes destruindo sua identidade e beleza) abandonando a postura de considerar aquilo que decorreu do meteoro do movimento moderno.

Com um novo olhar para a diversidade e especificidade, a arquitetura pós-moderna não deveria seguir regras ou métodos, mas estabelecer relação de significância entre usuário, edifício, local, cultura e memória. É neste período que há o rompimento com o raciocínio projetual que os arquitetos modernistas carregavam, já que agora cada projeto teria a sua particularidade em meio a uma sociedade em massa e globalizada. Além disso, o adorno e o decorativismo são o ponto chave para esse novo estilo, uma vez que o pósmoderno faz releituras de estilos passados afins de que se busque o significado e fuja do igualitarismo.

Neste sentido, Cavalgante (2007) diz que essa fase está fortemente ligada à globalização, em que se encontra uma sociedade em massa, influenciada pelas mídias digitais e portadoras de avanços tecnológicos, tal como o DVD, CD e MP3 o computador e o telefone celular. Diante disso, vivemos um momento insólito em que o futuro tem se tornado um lugar vazio, em um período que tinha como objetivo tecer a alteridade, mas o resultado foi uma nova sociedade ou sociedade do consumo, sem entendimento da Nova Ordem Mundial.

Neste período, os arquitetos utilizavam uma serie de estratégias para estabelecer a crítica do modernismo, de forma que valorizava a história, reabilitada na composição arquitetônica e a cultura popular. Assim, Robert Venturi, chama atenção pelas formas de arquitetura vernácula, decorrente de uma estética popular. Aldo Rossi, por sua vez, preocupou com a relação entre o projeto e o entorno de tal forma que esta postura de aliança entre o novo e o velho convencionou-se chamar de contextualismo (PINTO, 2008).

Além disso, Ricardo Bofill apresenta em seus projetos ser um arquiteto conceituador, famoso por investigar estilo e elegância clássica, misturando com raízes ibéricas e crítica ao suposto simplismo da industrialização (FLORENCE, 2015). 


\section{METODOLOGIA}

Este artigo é fruto de uma investigação bibliográfica e toma como recorte a vida do arquiteto catalão Ricardo Bofill, afim de compreender seu estilo arquitetônico e analisar a obra Walden 7. Desta forma, a pesquisa se estruturará em uma abordagem qualitativa, pois segundo Minayo (2001) este método de análise corresponde a questões particulares que se preocupam com a ciência social e com uma realidade não quantificada e que o a complexidade do objeto em estudo deve ser analisada de forma específica e contextualizada.

Assim, a pesquisa qualitativa possui metodologia indutivo, segundo o qual parte da observação, da análise dos fatos particulares, dos registros para compor um quadro compreensivo para então constituir a generalização universal, ou seja, a teoria. O processo de indução vale-se do princípio do empirismo, no qual o conhecer é dar significado à realidade (KÖCHE, 1997, p. 62).

\section{RESULTADO}

Nascido em 1939 na cidade de Barcelona, Ricardo Bofill Levi estudou no Liceu francês e depois na Escola Técnica Superior de Arquitetura de Barcelona, onde, em 1957, foi expulso por pertencer a uma associação política comunista. Em seguida, viajou para a Suíça que continuou os seus estudos na Universidade de Genebra (OLIVA, 2017).

Em 1963 Bofill cria o Taller de Arquitectura (Oficina de Arquitetura), um estúdio que conta com sociólogos, além de arquitetos e engenheiros, com condicionantes de abordar projetos de diferente natureza em diversas partes do mundo, adaptando-os às realidades culturais de cada lugar (BOFILL, 2017).

Além de ser um dos melhores representantes do estilo pós-moderno da arquitetura contemporânea, Bofill foi eleito membro honorário do Instituto Americano de Arquitetos, e considerado um dos influentes do mundo pelo desenvolvimento de linguagem moderna na elaboração de obras de arquitetura e de urbanismo no planejamento das cidades. (FLORENCE, 2015)

Suas primeiras obras aparecem elementos tradicionais da arquitetura mediterrânea e especificamente catalães e que mais tarde, sua linguagem é renovada, com um grande dinamismo quando liga casas, criando um sistema que serve como alternativa ao bloqueio racionalista, para resolver os problemas de seus projetos maiores. (BOFILL,2017).

Além disso, Florence (2015) pontua que o trabalho de Ricardo se manifesta através da nova vanguarda, que experimentava novos caminhos, com o uso de materiais cada vez mais industrializados, recuperando certo monumentalismo e se conectando com linguagens clássicas, como colunas ou arcos, recursos típicos da arquitetura pós-modernista.

Em 1971 Bofill promove uma segunda oficina, com obras mais carregadas de elementos típicos da arquitetura culinária francesa, praticando uma espécie de megaclassismo facilmente criticado. Isso leva a um ecletismo confuso em que há uma série de estilos historicistas diferentes.

Como exemplo La Petite Cathedrale (1971), um projeto demonstra como a metodologia geométrica pode ser usada de forma diferente para produzir objetos de significância e uso diversificado, como exemplo, o edifício que é realizado através do uso de espaços que evocam as catedrais góticas, a inspiração gótica é uma resposta ao desejo de criar um macroprojeto significativo e reconhecível na cidade, além do desejo de oferecer às classes média e trabalhadora o gozo de espaços monumentais, até então o privilégio das 
classes dominantes. Novamente, a metodologia geométrica de combinar volumes cúbicos no espaço é evidenciada em sua obra.

Como também o bloqueio perimetral dramático Le Espaces d'Abraxas (1978-83), que a equipe acrescenta atrás do site oficial que é um monumento urbano que marca o início da nova cidade, edifícios que estão dispostos em um espaço barroco, mais francês em algumas áreas, mais mediterrâneo em outros, para constituir um ótimo espaço público em que a monumentalidade é o pano de fundo da área mais nobre do novo empreendimento residencial. Em virtude disto, "Les Espaces d'Abraxas" tornou-se o símbolo e o ponto de referência para uma grande parte do Vale do Marne. Assim ambos os projetos são compreendidos como verdadeiros monumentos habitados.

Outro projeto é Walden 7 aborda grande parte dos problemas da vida urbana, que tem a ideia de proporcionar espaços e jardins públicos para que os residentes pudessem desfrutar de uma melhor qualidade de vida. Ele incorpora os conceitos de magnitude arquitetônica, bem como um recurso novo e enriquecedor no ambiente suburbano que a rodeia além disso, tenta fornecer uma solução para os problemas da vida nas cidades de hoje, onde há falta de comunidade, de atividade coletiva, de espaço público à disposição do indivíduo (BOFILL, 2017).

De inúmeros projetos, como de hotéis, aeroportos e torres de escritórios, Taller de Arquitectura, ocupa em 1973, sua sede, onde era uma antiga fábrica de cimento abandonada, um complexo industrial da virada do século e que contrapõe o funcionalismo empregado pelo movimento moderno. Para ele é um trabalho de precisão, que revela formas ocultas e recupera certos espaços, comparáveis ao trabalho do escultor, cuja tarefa é confrontar o material. Além disso, integra várias linguagens históricas em oposição à arquitetura vernacular.

Essa ideia mostrou que qualquer espaço pode ser alocado e que a função é flexível enquanto a forma. Diante disso, o projeto se adapta a qualquer espaço para uma nova função, não importando o quão diferente ele pode ser a partir do original.

\section{DISCUSSÃO}

Localizado nos subúrbios de Barcelona e construído em 1974, Walden 7 é um complexo de apartamentos com catorze pavimentos, formado por dezoito torres e cinco pátios internos. A equipe de Bofill descreve em seu site o edifício como um labirinto vertical contendo mais de quatrocentos apartamentos de tamanhos variados, ligados por um sistema complexo de passarelas e varandas em diferentes níveis. Com raras exceções, os apartamentos têm vista para o lado externo e para os pátios internos. Possui balcões espalhados por toda sua verticalidade, oferecendo vista para os usuários e duas piscinas na cobertura. Bofill toma como conceito para a obra a formação de uma comunidade vertical em seu prédio, se utilizando de inúmeros lugares de encontro e permanência em sua extensão como partida para atingir seu objetivo.

Ricardo Bofill tenta resolver grande parte dos problemas da vida urbana moderna em sua obra, criando espaços e jardins coletivos para melhorar a qualidade de vida de seus moradores, como o pátio central (Figura 1) que funciona como uma extensão da rua e da praça de entrada. Compondo sua forma, existem aberturas enormes que iluminam os ambientes internos do edifício e oferecem vista para a paisagem urbana. O prédio se situa no mesmo terreno que as ruínas de uma antiga fábrica de cimento, onde funciona hoje o escritório da Ricardo Bofill Taller Arquitetura (NAVARRETE, 2011). 
Figura 1: pátio central do edifício

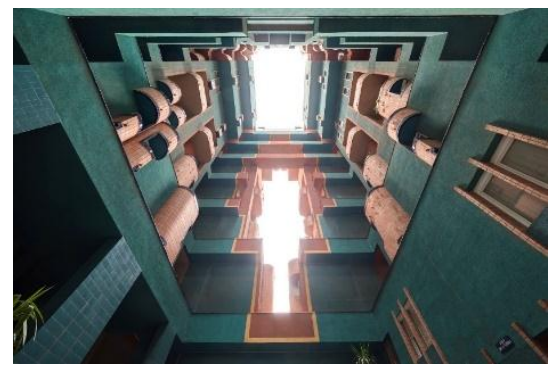

Fonte: Archdaily, 2016

Sua forma e estrutura são extremamente complexas, criando um ambiente com uma configuração espacial totalmente surpreendente e dinâmica. Suas habitações são formadas por módulos de trinta metros quadrados, dispostos em um ou dois pavimentos, variando de estúdios de um módulo até apartamentos de quatro módulos (Figura 2). A fachada remete a uma grande fortaleza na cor vermelha, enquanto seus pátios externos trazem um elemento animado, possuindo fortes cores em suas paredes como o azul, amarelo e o violeta (NAJA, 2013).

Figura 2: Três tipologia residencial distintas.
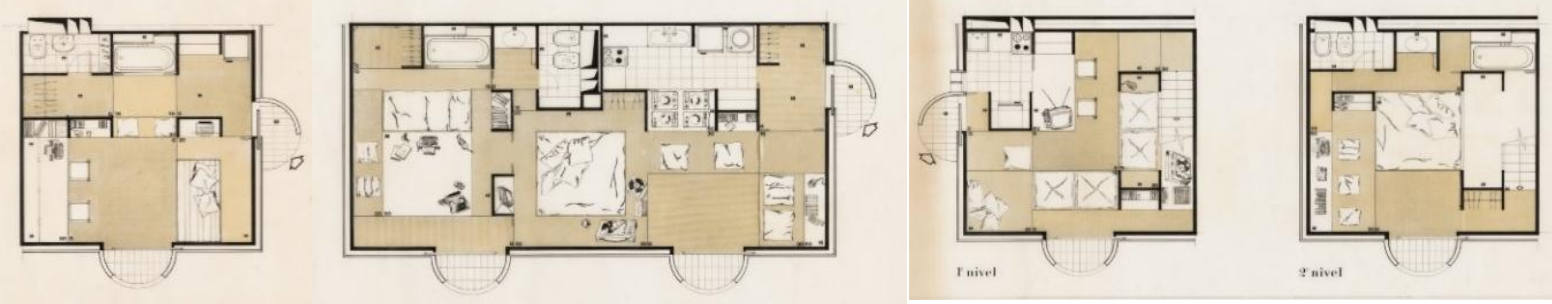

A construção deste edifício ocorreu durante a pós-modernidade, que é marcada por uma forte crítica ao movimento moderno. Walden 7 expressa essas críticas através de sua forma e suas funções, onde ao invés de usar uma forma pura, Ricardo se utiliza da superposição e da justaposição dos apartamentos para formar uma fachada completamente dinâmica. Relaciona a construção com o entorno com auxílio de gigantescas aberturas e pátios internos ligados à cidade.

Estabelece uma tentativa de criação de comunidade, uma vez que disponibiliza uma vasta quantidade de lugares de encontro em toda a extensão do prédio, além de espaços coletivos na cobertura e nos pátios térreos, e varia os tamanhos e usos dos apartamentos para que se tenha uma variedade maior de pessoas.

\section{CONCLUSÃO}

A linha de montagem do Modernismo e seus questionamentos estéticos estiveram presentes na geração de Bofill, por isso encontramos uma sensibilidade a tecnologia e certa crítica a seus exageros, crítica que podemos enxergar no projeto da readequação de uma antiga fábrica de cimento para abrigar o Taller de Arquitectura e sua residência própria, em outra ala da planta industrial. Sem adornos, e com uma parcimônia na aplicação de materiais 
refinados, apenas fazendo reparos simples às estruturas das chaminés e silos, uma provocação à proposta do funcionalismo moderno: espaços gigantescos utilizados como salas de reunião, salas de jantar e dormitórios. Dessa forma, a abordagem de Ricardo Bofill é extremamente (neo) historicista, promovendo esta relação, na verdade, de uma maneira há algumas décadas bastante difundida: resgatando elementos compositivos de um leque classicista, construídos com tecnologia atual. Neste aspecto, Bofill tratou sua arquitetura como muitos 'neo-historicistas', e em alguns casos com mais 'naturalidade' que outros das últimas décadas (apesar das referências explícitas à arquitetura clássica, a naturalidade mostra-se em uma utilização mais 'moderna', retirando os excessos que muitos arquitetos mantinham quando a referenciavam). Sua intenção foi recuperar valores históricos e simbólicos da arquitetura no sentido de devolver seu aspecto popular.

\section{REFERÊNCIAS}

BOFILL, R. La Fabrica. Apresentação da obra. Disponível em: http://www.ricardobofill.com/la-fabrica/read/. Acesso em 24 de novembro de 2017

BOFILL, R. La Petite Cathedrale. Apresentação da obra. Retirado no site http://www.ricardobofill.com/projects/la-petite-cathedrale/. Acesso em 24 de novembro de 2017

BOFILL, R. Le Palais d'Abraxas. Apresentação da obra. Disponível em: http://www.ricardobofill.com/projects/les-espaces-dabraxas/. Acesso em 24 de novembro de 2017

BOFILL, R. Walden 7. Apresentação da obra, 2017. Disponível em: http://www.ricardobofill.com/projects/walden-7-2/. Acesso em 24 de novembro de 2017.

CAVALGANTE, M. B. O conceito de pós-modernidade na sociedade atual. João Pessoa: Paraíba, 2007.

ESPERANDIO, M. R. G. Para entender pós-modernidade. São Leopoldo: Sinodal, 2007.

FLORENCE, L. Ricardo Bofill: a arquitetura de autor no século 20. São Paulo: São Paulo. 2015. Edição 251. Disponível em: http://au17.pini.com.br/arquiteturaurbanismo/251/artigo338522-2.aspx. Acesso em 22 de novembro de 2017.

GIDDENS, A. As consequências da modernidade. São Paulo: Editora UNESP, 1991.

JAMENSON, F. Reflexões sobre pós-modernidade, justiça e filosofia. Palestra realizado pelo café filosófico CPFL. Disponível em: https://www.youtube.com/watch?v=huyUqPvT7Qs. Acesso em 14 de novembro de 2017.

KÖCHE, J. C. Fundamentos de metodologia científica: teoria da ciência e iniciação à pesquisa. 22. ed. São Paulo: Vozes, 2004.

MINAYO, M. C. de S. Pesquisa Social: Teoria, método e criatividade. 18 ed. Petrópolis: Vozes, 2001. 
NAJA, R. AD classics: Walden 7/Ricardo Bofill. 2013. Disponível em: https://www.archdaily.com/332142/ad-classics-walden-7-ricardo-bofill. Acesso em 24 de novembro de 2017.

NAVARRETE, J. E. Habitação multifamiliar contemporânea: lotes aéreos para moradias flexíveis. Trabalho de conclusão de curso pela UNESP, 2011.

PINTO, O. L. F. Tendência da Arquitetura Moderna. Angola, 2008.

PORTOGHESI, P. Depois da arquitetura moderna. São Paulo: Martins Fontes, 2002.

SULLIVAN, M. A. Walden 7. 2015. Disponível em: https://www.bluffton.edu/homepages/facstaff/sullivanm/spain/barcelona/walden/walden. html. Acesso em 24 de novembro de 2017. 